\title{
Full mouth rehabilitation using zirconia crown in severe worn dentition: a case report
}

\author{
Jung-Hyun Park, Sang-Hyuk Sohn, Sung-Am Cho* \\ Department of Prosthodontics, School of Dentistry, Kyungpook National University, Daegu, Republic of Korea
}

The progressive attrition of teeth is a normal process by aging. However, excessive tooth wear with decreased vertical dimension of occlusion and collapse of occlusal plane may cause pathologic pulpal condition, occlusal disharmony and functional disorders. In this case, a patient with severely worn dentition was treated. Diagnostic wax-up was performed at the increased vertical dimension. After evaluation of provisional restorations for 12 weeks, final restorations were fabricated with zirconia crown and routine clinical assessments were made. Esthetically and functionally satisfactory results were obtained. (J Dent Rehabil Appl Sci 2016;32(3):202-8)

Key words: worn dentition; vertical dimension; zirconia; full mouth rehabilitation

\begin{abstract}
서론
치아의 마모(tooth wear)는 일생에 걸쳐 치아의 교합면 에서 점진적으로 일어나는 정상적인 과정이다. 과도한 교 합면 마모는 내인적 혹은 외인적 원인으로 생리적 마모 가 급속화 될 때 발생되며 ${ }^{1}$ 교합 부조화, 전방유도의 붕 괴, 치수병변, 기능장애, 턱관절 및 저작근에 병리적인 문 제를 야기한다. 병적인 교합면 마모(pathologic wear)의 진행을 막기 위해서 원인에 대한 분석이 필수적이고 이를 통해 본래의 기능, 심미, 발음 등을 회복해야 한다.

Dawson에 따르면 성인의 경우 마모와 함께 발생하 는 치조골의 성장으로 일정한 수직고경을 유지하기 때 문에, 수복 치료를 시작하기 전에 환자의 수직고경에 대 한 신중한 평가가 필요하다. ${ }^{2}$ Turner와 Missirlian은 심 한 마모를 보이는 환자를 3가지군으로 분류하며 수직고 경의 소실은 없으나 보철 수복 공간이 부족한 환자는 교 정적 처치나 수술적인 방법, 현재의 수직고경의 수정 등

*Correspondence to: Sung-Am Cho

Professor, Department of Prosthodontics, School of Dentistry, Kyungpook National University, \#2175 Dalgubeoldae-ro, Jung-gu, Daegu, 41940, Republic of Korea

Tel: +82-53-600-7672, Fax: +82-53-427-0778, E-mail: sacho@knu.ac.kr

Received: July 6, 2016/Last Revision: July 26, 2016/Accepted: August 8, 2016
\end{abstract}

을 통해 가용 공간을 확보할 수 있다고 하였다. 만약 공 간 확보를 위해 수직고경을 증가시킬 때에는 수복 재료 를 위한 최소한의 증가만 허용하고, 임시 수복을 이용한 장기간의 관찰로 환자의 순응도를 평가해야 함을 강조 하였다. 그 외에도 교합관계를 변화시키거나 심미적인 이 유로도 수직고경을 수정할 수 있다고 하였다. ${ }^{3}$ 본 증례 에서는 광범위한 마모를 보이는 환자에서 수직고경의 증 가를 동반하여 computer aided design/computer aided manufacturing (CAD/CAM) 단일구조 지르코니아를 이 용해 전악 고정성 보철물로 수복 하였으며, 기능적인 면 과 심미적인 면에서 만족스러운 결과를 얻었기에 보고하 는 바이다.

\section{증례보고}

본 환자는 39세 남자로 교합면의 마모로 인하여 상악 좌우 구치부에서 저작 시 찌릿한 통증을 주소로 내원하

CopyrightC 2016 The Korean Academy of Stomatognathic Function and Occlusion. (c) It is identical to Creative Commons Non-Commercial License. 
였으며 안모의 개선을 원하였다. 알레르기 비염 이외의 다른 의과적 병력은 없었으며 야간 이갈이를 비기능적 습관으로 가지고 있었다. 구강 내 검사결과 하악 구치부 아말감 수복을 제외하고는 보철 수복의 이력이 없었으며 모든 치아에서 심한 마모 양상을 보였고 특히 상악 전치 부와 좌측 구치부에서 마모 정도가 심하였다. 좌측 소구 치부(\#24, 25, 34, 35)는 편측 가위 교합(scissors bite)이 였다. Temporomandibular joint (TMJ) series에서 턱관 절의 변이 등 이상 소견은 발견되지 않았다(Fig. 1,2).

Wax bite를 사용하여 중심위를 채득하고, 안궁이전 후 반조절성 교합기(KaVo PROTAR evo 7, KaVo Corp., Biberach, Germany)에 마운팅하여 진단 모형을 분석하 였다. 우선 좌측 소구치부의 가위 교합을 개선하기 위하 여 교정적인 치료를 선행하였다. 30 번대 구치부의 expansion을 위하여 schwarts장치를 사용하였고 수직 고경을 상승시키기 위하여 상악에서 bite plate를 사용하여 4개 월간 교정치료를 시행하였다. 동시에 상악 6전치의 삭제
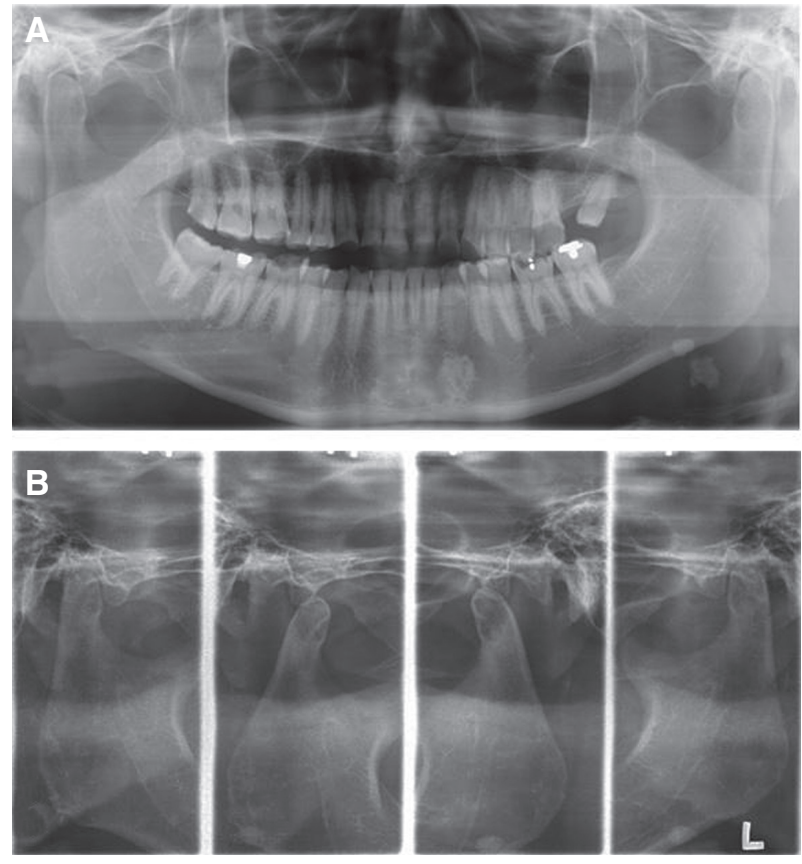

Fig. 1. (A) Panoramic view, (B) TMJ series before treatment. No evidence of pathologic change was seen. Centric occlusion and maximum opening.

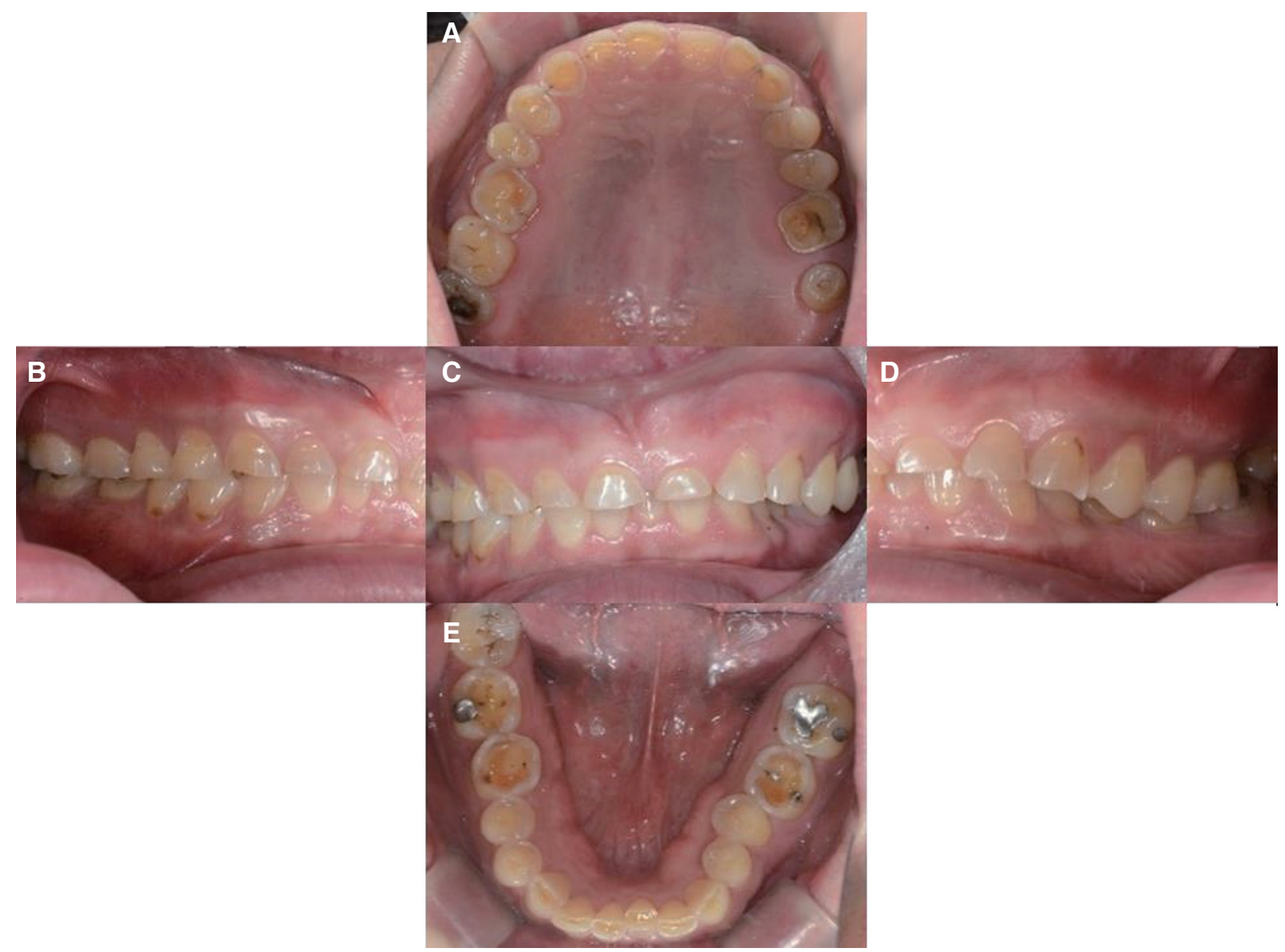

Fig. 2. Initial intraoral view. (A) Maxillary occlusal view, (B) Right lateral view, (C) Frontal view, (D) Left lateral view, (E) Mandibular occlusal view. 
량을 고려하여 근관 치료를 시행하였고 상악 좌측 제 2 대 구치에 보존적 술식을 병행하였다(Fig. 3).

교정치료가 완료된 후 진단모형을 제작하여 안궁이전 및 중심위 채득하고 전반적인 치질의 상태를 분석하였 다. 상악 전치부의 임상치관 길이는 $5 \mathrm{~mm}, 6 \mathrm{~mm}$ 로 3 - 4 $\mathrm{mm}$ 정도의 치관 길이가 더 필요한 상황이었고, 심미적인 보철물의 제작 공간을 위하여 $3 \mathrm{~mm}$ 수직 고경의 거상을 결정하였다. Incisal pin을 $3 \mathrm{~mm}$ 거상하여 진단 왁스업을 시행하였고 진단 납형을 복제하여 자가 중합 레진(Alike TM, GC America inc., Alsip, USA)으로 임시 수복물을 제작하여(Fig. 4) 약 12 주동안 환자의 기능적 적응 정도 와 심미적 만족감 등을 평가하였다. 적응 기간 동안 임시 수복물의 파절 및 마모가 나타나지 않았고 턱관절 통증 이나 불편감 없이 유지되어 최종 인상 채득을 시행하였 다.
Tooth tray를 제작하고 부가중합형 실리콘 인상재 (Aquasil Ultra LV, Densply Caulk, Milford, USA)를 사 용하여 인상 채득 후 작업모형을 제작하였다(Fig. 5 - 7). 임시 수복물을 제작할 때 결정된 고경을 바탕으로 부가 중합형 실리콘 교합인기재(Cresil bite, Creden)를 이용하 여 먼저 상, 하악 우측 구치부와 전치부에 임시 수복물을 장착한 채로 좌측의 교합을 인기하고, 좌측의 교합제와 전치부 임시치아를 장착한 상태로 우측의 교합을 인기하 고 좌우측 교합제를 장착한 상태로 전치부 교합을 앞서 얻은 교합제와 연결시켜 교합 관계를 채득하였다(Fig. 6). 심미적인 요구와 야간 이갈이 악습관 등의 이유로 전 악을 지르코니아 크라운(ceramill)으로 최종 수복 하였 다. Milling wax를 제작하여 환자의 구강 내 시적하여 확 인한 후 최종 수복물을 제작하였다(Fig. 8).

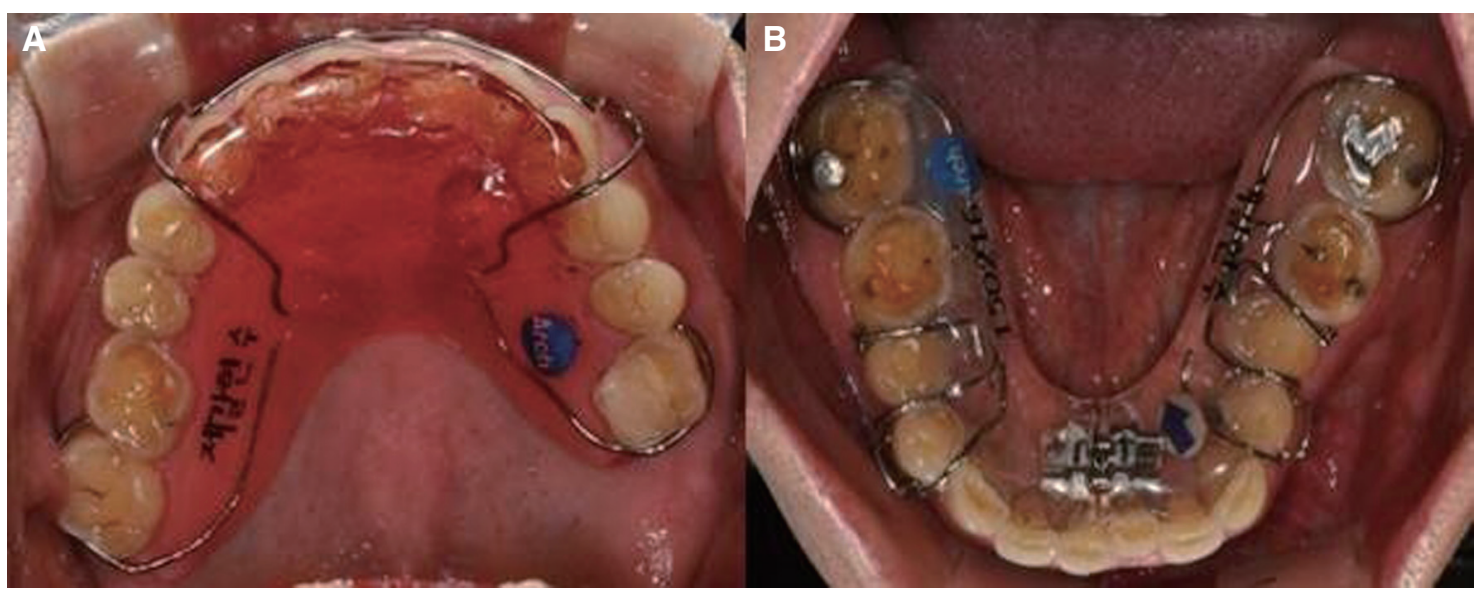

Fig. 3. Orthodontic treatment. (A) Bite plate on maxilla, (B) Schwarts on mandible.

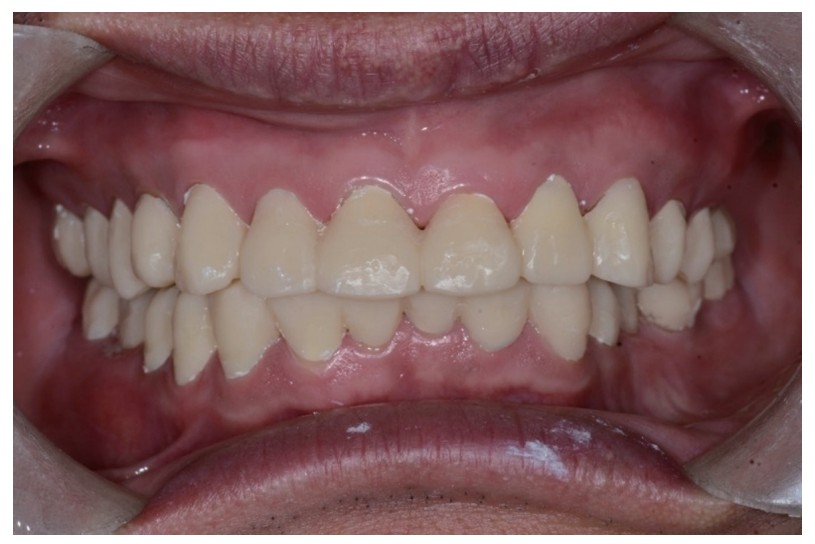

Fig. 4. Temporary prosthesis. 


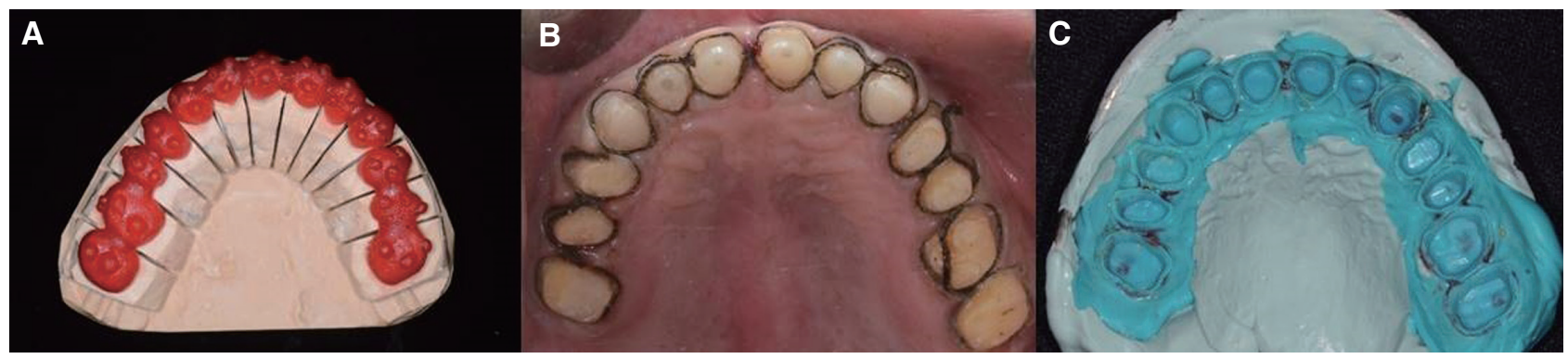

Fig. 5. Maxilla. (A) Making tooth tray, (B) Teeth preparation and code packing, (C) Final impression taking.
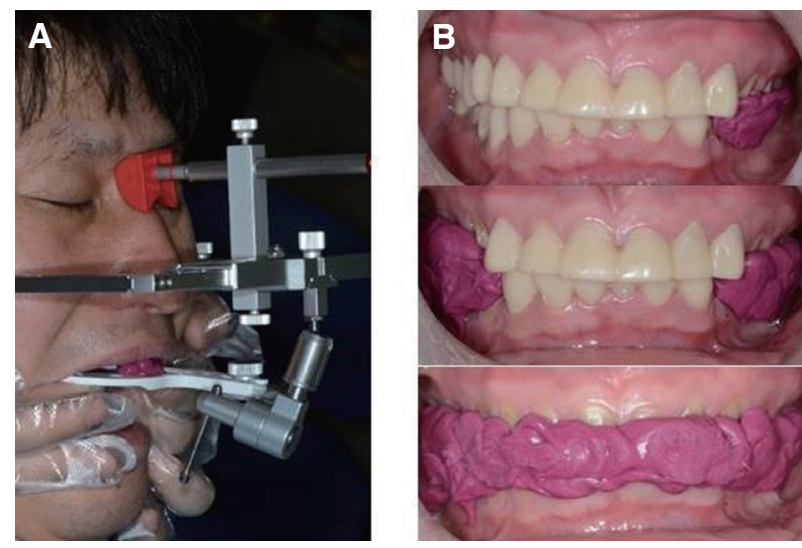

Fig. 6. (A) Facebow transfer, (B) Bite registration.

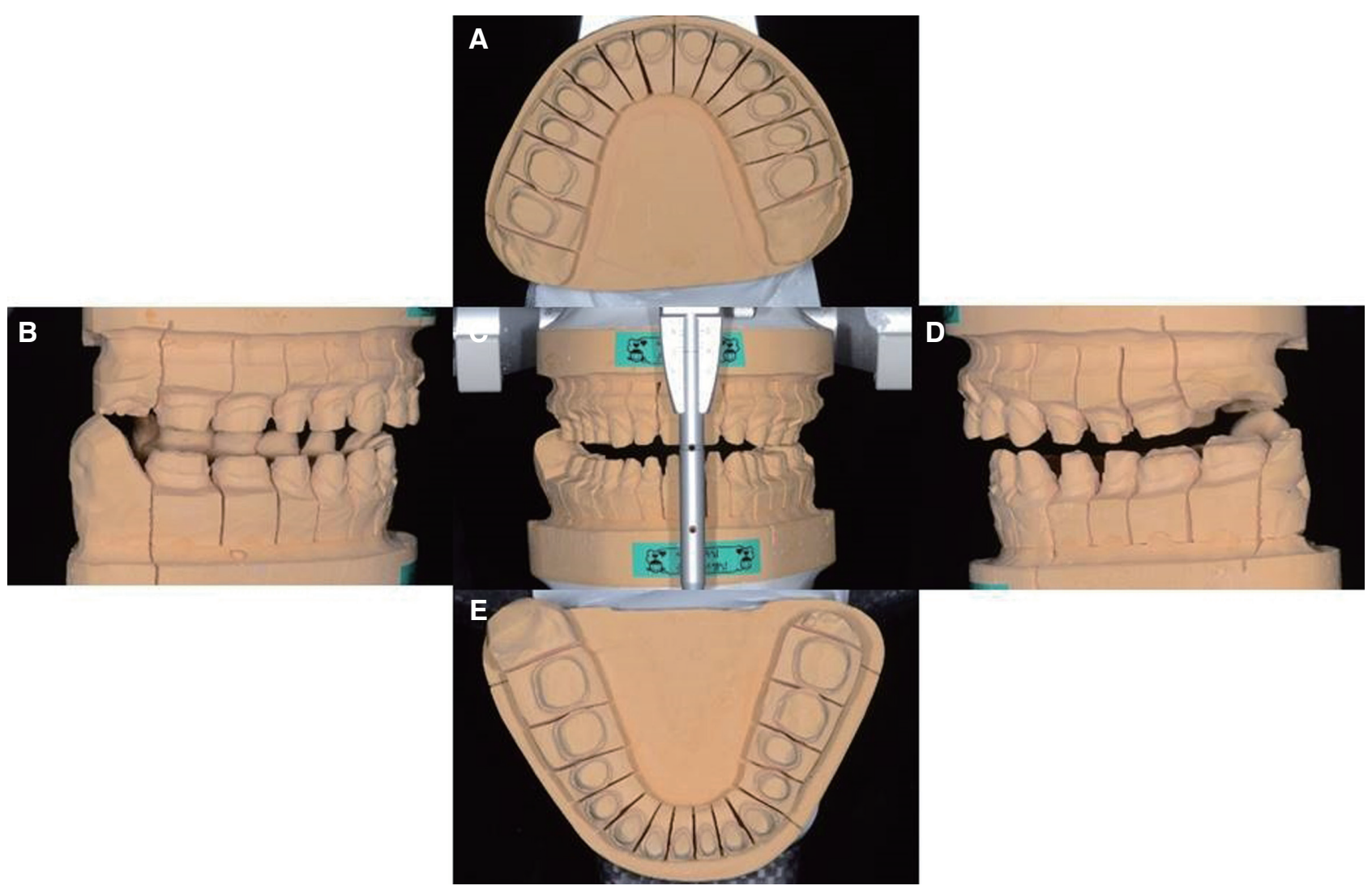

Fig. 7. Maser cast. (A) Maxillary occlusal view, (B) Right lateral view, (C) Frontal view, (D) Left lateral view, (E) Mandibular occlusal view. 


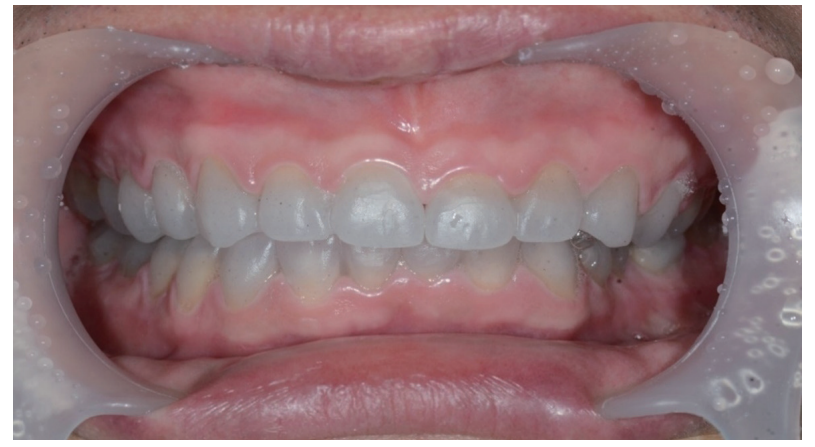

Fig. 8. Milling wax try-in.
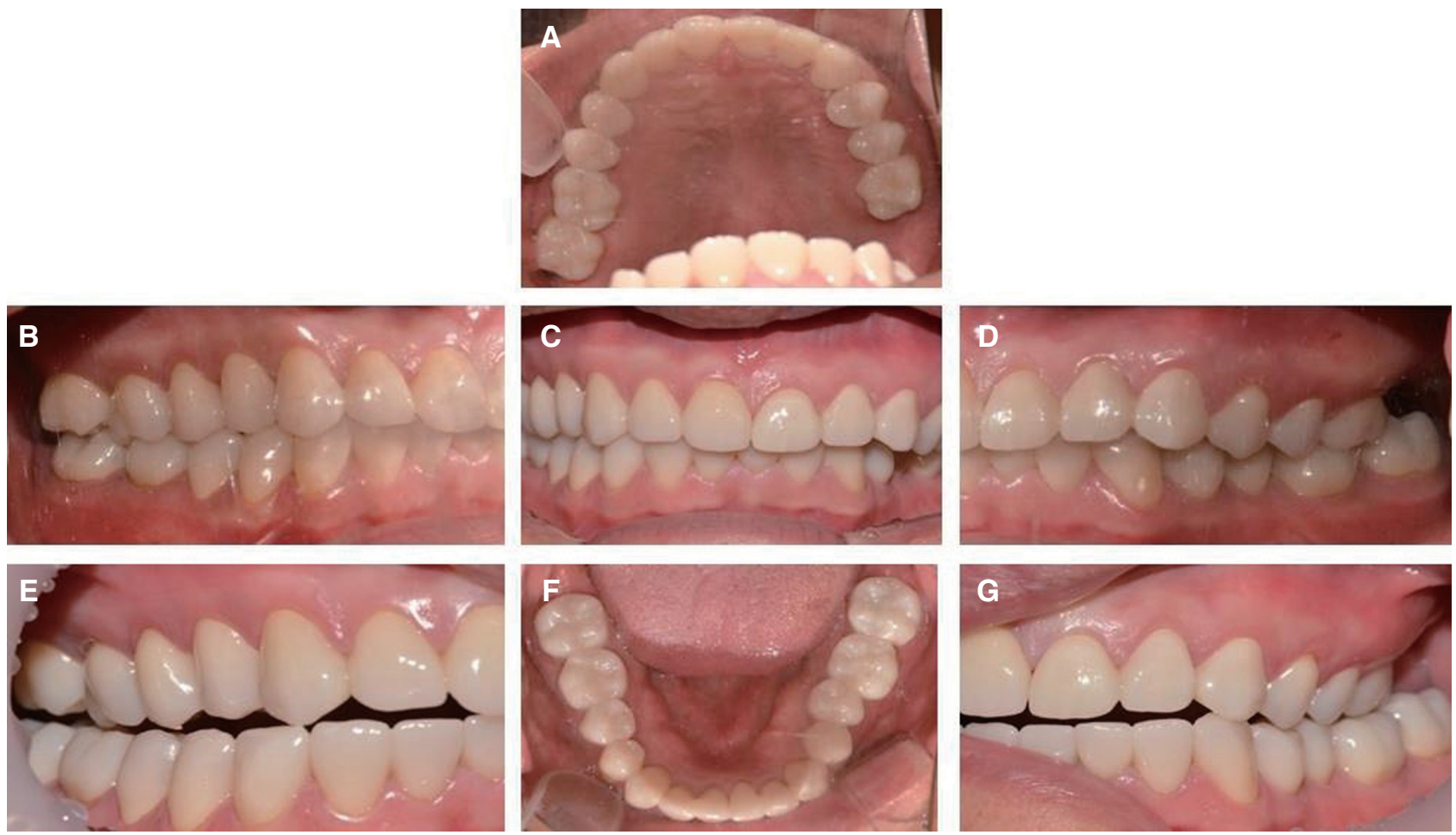

Fig. 9. Definitive prosthesis. (A) Maxillary occlusal view, (B) Right lateral view, (C) Frontal view, (D) Left lateral view, (E) Right working movement, (F) Mandibular occlusal view, (G) Left working movement.

중심위에서 양측 구치부에서 균등한 접촉을 부여하였 고 측방 운동시 견치유도를 부여하여 구치부 이개가 가 능하도록 교합조정 하였다(Fig. 9). 임시 시멘트로 접착하 여 3개월 사용 후 불편감이 없음을 확인한 후 내면을 샌 드블라스트 처리하고 프라이머 처리한 후 레진 시멘트 (Rely X Unicem, 3M ESPE, St. Paul, MN, USA)를 이용 하여 최종 접착 하였다. 환자의 야간 이갈이 습관을 고려 하여 연질의 교합안정장치를 제작하여 착용하도록 지시 하고, 구강위생 관리 교육을 시행하다.

술 후 파노라마상과 측두하악 관절상에서 특이한 병적
변화는 관찰되지 않았다. 치료 전, 후와 비교하여 환자는 심미적, 기능적으로 만족하였다.

\section{고찰}

치아의 마모를 보이는 환자는 보통 심미적인 이유, 기 능적인 이유, 지각 과민증의 증가 때문에 진료실을 내원 한다. 이때 치아의 마모가 일어난 원인이 무엇이며 수직 고경이 감소되었는지 평가 하여 보철 수복 전에 개개인 에 맞게 정확한 진단을 하는 것이 가장 중요하다. 
Turner와 Missirlian에 따르면 치아의 마모의 원인은 크게 5 가지로, 본 증례의 경우 야간 이갈이의 악습관이 있었다. ${ }^{3}$ 야간 이갈이는 grinding과 clenching을 포함하 며 occlusal prematurities 혹은 interference 때문이거나 스트레스에 의한 것으로 생각되고 있으나 완전히 원인이 규명되지 않았다. ${ }^{4}$ 하지만 확실한 것은 하나의 방법으로 이갈이를 제거하거나 감소시키려고 하는 것은 효과적이 지 않다는 것이며 Dawson에 따르면 교합장애를 제거하 면 이갈이의 증상이 많이 개선된다는 것이다. ${ }^{2}$ 본 증례의 경우 과도한 마모의 진행을 막기 위하여 전악을 수복하 여 교합평면을 재구성 하였고 비중심위 하악 운동 경로 중에서 모든 구치의 이개가 일어나도록 편심위에서 교합 관계를 부여하였다.

일반적으로 과도한 치아의 마모로 인하여 수직고경이 감소되었을 것이라고 생각을 하지만 교합면의 마모량과 같은양으로 치조골의 신장이 일어난 경우라면 interocclusal space가 감소하였지만 수직고경은 일정하게 유지 되고 있으며, 단순히 치아의 수직길이를 증가 시킨다면 저작근의 피로, 두통, 치아의 통증 등의 문제가 발생할 것이다. 본 환자의 경우 Turner와 Missirlian category II 에 해당하는 경우로 수직고경의 소실이 없었고 구치부의 interocclusal space가 적절하였지만 전치부 stop 형성과 심미적 형태를 위하여 최소한의 $3 \mathrm{~mm}$ 수직고경을 거상 하였다. Carlsson은 $4 \mathrm{~mm}$ 까지 수직 고경을 증가 시킨 경 우 근활성도에 있어서 큰 변화는 없다고 보고한바 있다. ${ }^{5}$ 근신경계의 적응범위를 넘어서지 않는지 확인하기 위하 여 12 주간 임시치아를 사용하였으며 특별한 이상이 없었 으므로 최종인상채득을 결정하였다.

심미성의 개선을 도모하고 야간 이갈이의 악습관을 고 려하여 전악을 완전 지르코니아 크라운 수복으로 결정 하였다. 단일 구조 지르코니아 보철물은 심미적이면서도 높은 강도를 가지고, veneering ceramic이 올라가지 않 기 때문에 도재의 파절이 없고 악간 공간이 부족한 환자 들의 치료에 적절히 사용될 수 있다. 그리고 강도가 강한 지르코니아를 전 두께에 걸쳐 제작함으로써 보다 보존적 인 치아 삭제로도 기존의 전부 도재관보다 강도를 확보 하기 쉽다는 장점이 있다. Albashaireh 등의 two-body in vitro 마모도 검사 결과 고도로 연마된 지르코니아는 가 장 마모를 적게 일으키며 그 결과 고도로 연마된 지르코 니아와 대합 될 경우 마모가 아주 적을 것이라고 언급하 였다. ${ }^{6}$ 보철물 장착 후 Turner와 Missirlian이 제시한 것처 럼 예방적 목적의 교합 안정 장치를 제작하였다. 정기적
인 내원을 통한 경과관찰이 앞으로도 중요할 것으로 생 각된다. ${ }^{3}$

\section{결론}

본 증례에서는 광범위한 마모를 보이는 환자에서 진 단 모형의 분석을 통하여 수직고경의 증가를 결정하였고 약 12 주간 임시 수복물을 사용하여 환자의 적응 여부와 심미성을 평가하였다. 임시 수복물을 바탕으로 CAD/ $\mathrm{CAM}$ 단일구조 지르코니아를 이용해 전악 고정성 보철 물로 수복 하였으며, 기능적인 면과 심미적인 면에서 만 족스러운 결과를 얻었다. 장기적인 경과 관찰을 통하여 지속적인 평가가 필요할 것이다.

\section{ORCID}

Jung-Hyun Park http://orcid.org/0000-0002-7587-5608 Sung-Am Cho http://orcid.org/0000-0002-8315-7833

Sang-Hyuk Sohn http://orcid.org/0000-0003-4537$763 \mathrm{X}$

\section{References}

1. Verrett RG. Analyzing the etiology of an extremely worn dentition. J Prosthodont 2001;10:224-33.

2. Dawson PE. Functional occlusion - from TMJ to smile design. 1st ed. St. Louis; Mosby; 2006. p. 4303.

3. Turner KA, Missirlian DM. Restoration of the extremely worn dentition. J Prosthet Dent 1984;52: 467-74.

4. Ramfjord SP. Bruxism, a clinical and electromyographic study. J Am Dent Assoc 1961;62:21-44.

5. Carlsson GE, Ingervall B, Kocak G. Effect of increasing vertical dimension on the masticatory system in subjects with natural teeth. J Prosthet Dent 1979;41:284-9.

6. Albashaireh ZS, Ghazal M, Kern M. Two-body wear of different ceramic materials opposed to zirconia ceramic. J Prosthet Dent 2010;104:105-13. 


\section{마모가 심한 환자에서 지르코니아 크라운을 이용하여 전악 수복한 증례}

\section{박정현, 손상혁, 조성암*}

경북대학교 치과병원 치과보철학교실

점진적인 마모는 정상적인 과정이지만 교합면의 마모가 병적으로 과도하게 진행되어 교합평면이 붕괴된 경우 교합, 저작 근, 치수병변 등의 문제가 나타날 수 있다. 본 증례에서는 광범위한 마모를 보이는 환자에서 수직고경을 증가하여 임시 수복물을 제작한 후 약 12 주간 환자의 적응 여부와 심미성을 평가하였다. 임시 수복물을 바탕으로 CAD/CAM 단일구 조 지르코니아를 이용해 전악 고정성 보철물로 수복 하였으며, 기능적인 면과 심미적인 면에서 만족스러운 결과를 얻었 기에 이를 보고하는 바이다.

(구강회복응용과학지 2016;32(3):202-8)

주요어: 마모; 수직고경; 지르코니아; 전악 수복 